\title{
A aprendizagem da escrita de textos com o Self-Regulated Strategy Development (SRSD)
}

\author{
Learning to write texts with Self-Regulated Strategy Development (SRSD) \\ Sara Ferreira, Maria Prata, Isabel Festas, Maria Helena Damião \\ Faculdade de Psicologia e de Ciências da Educação da Universidade de Coimbra
}

\begin{abstract}
Resumo
Neste trabalho, apresenta-se o estudo quase experimental, com pré-teste, pós-teste e follow-up, $O$ ensino da escrita através do Programa de Desenvolvimento de Estratégias de Autorregulação (SRSD) (SFRH/BD/84392/2012), que decorreu em duas escolas do ensino básico, nas turmas do $8 .^{\circ}$ ano de escolaridade.

Pretendemos testar a eficácia do ensino de estratégias de escrita e de autorregulação, tal como constam no SRSD, pelo que na escola que constituía

o grupo experimental foram ensinadas as estratégias de escrita do texto expositivo e na escola que compunha o grupo de controlo foram treinadas as estratégias de escrita do ensaio de opinião.

Palavras-chave: autorregulação da aprendizagem, ensino da escrita, Self-Regulated Strategy Development (SRSD), tipologias textuais
\end{abstract}

\begin{abstract}
In this paper, we will present the quasi-experimental study with pre-test, post-test and follow-up, The teaching of writing through the Self-Regulated Strategy Development (SRSD) model (SFRH / BD / $84392 / 2012$ ), that was applied to $8^{\text {th }}$ grade students in two middle schools.

We intend to test the effectiveness of the SRSD writing and self-regulation strategies' instructions. Therefore in the experimental group, students were taught the expository text's writing strategies. On the other hand, students in the control condition received the instruction on opinion essay writing strategies.

Keywords: self-regulation learning, writing instruction, Self-Regulated Strategy Development (SRSD), text genres
\end{abstract}

Sendo considerada uma tarefa complexa, não é de todo surpreendente que os alunos portugueses manifestem dificuldades na aquisição e domínio da composição escrita de textos que, aliás, têm sido evidenciadas em estudos nacionais e internacionais (GAVE, 2011; GIASE, 2004/2005; Sousa, 2012). Com o intuito de ajudar a ultrapassar esta lacuna, investigações na área verificaram os benefícios da instrução explícita desta tarefa.

O Self-Regulated Strategy Development (SRSD) é um modelo de instrução de estratégias de escrita e de autorregulação, cuja eficácia tem sido amplamente comprovada (Graham \& Perin, 2007; Harris et al., 2008).

De seguida, apresenta-se o estudo quase experimental $O$ ensino da escrita através do Programa de Desenvolvimento de Estratégias de Autorregulação (SRSD) (SFRH/BD/84392/2012) que tem como objetivos principais adaptar as estratégias do SRSD referentes à planificação e composição escrita do ensaio de opinião e do texto expositivo, e verificar os efeitos da sua instrução em alunos do $8 .^{\circ}$ ano de escolaridade. Sendo este domínio uma competência transversal a todo o currículo, pretendemos ainda verificar a eficácia do ensino de estratégias de escrita e de autorregulação na composição de textos e no desempenho escolar geral dos alunos.

Este estudo, com pré-teste, pós-teste e follow-up, decorreu durante o ano letivo de 2013-2014, em duas escolas do ensino básico do concelho de Coimbra, correspondendo uma delas ao grupo experimental e a outra ao de controlo. Desenvolveram-se dois programas diferentes de ensino da composição escrita, efetivados em 12 sessões, de 45 minutos cada, nas aulas de Português, tendo sido lecionados pelas professoras desta disciplina. O grupo experimental aprendeu as estratégias de composição escrita do texto expositivo do SRSD, as quais foram previamente adaptadas para a língua e contexto portugueses. No grupo de controlo foram ensinadas as estratégias para a composição escrita do ensaio de opinião que tinham sido testadas no âmbito de um projeto anterior ("Ensino de Estratégias de Escrita" /PTDC/CPE-CED/102010/2008). As lições dos dois programas tiveram por base mnemónicas, próprias de cada tipologia textual. Através daquelas, foram ensinadas de forma explícita, aos alunos, a estrutura dos textos, os diferentes processos inerentes à sua redação e estratégias de autorregulação.

As professoras participantes do estudo realizaram uma oficina de formação, com a duração de 50 horas, ao longo de todo o ano letivo. 


\section{A importância do conhecimento sobre as tipologias textuais}

O ensino da escrita é obrigatório e imprescindível para o sucesso académico. $O$ sistema educativo deve promover esta competência, contudo, como já foi referido, os alunos portugueses têm revelado dificuldades, nomeadamente na composição de textos (GAVE, 2011; GIASE, 2004/2005; Sousa, 2012).

Vários autores (Carvalho, 2002; Duarte, 2008; Neves \& Oliveira, 2001; Niza et al., 2011) apontam como possível origem destas dificuldades problemas que se prendem com o ensino da escrita, destacando a discrepância entre as orientações curriculares e a sua aplicação prática. Entre as causas mais prováveis contam-se, por exemplo, a primazia dada às componentes convencional, linguística e mecânica da escrita, em detrimento da cognitiva, e o pouco tempo despendido nas aulas para trabalhar a escrita fora dos momentos destinados à sua avaliação. Também neste sentido, Niza et al. (2011) refere que o facto de os alunos escreverem pouco, se deve à incapacidade dos professores para corrigirem os seus textos. Por outro lado, Carvalho (2002, p. 95) vai mais longe na tentativa de sintetizar as linhas principais que descrevem a sua abordagem pedagógica declarando que nas aulas de Português "a escrita é mais veículo de comunicação do que objeto de ensino-aprendizagem".

Reconhecendo estas dificuldades, o Ministério da Educação e da Ciência, nos Relatórios dos Exames Nacionais dos últimos anos, tem repetido o apelo do reforço das estratégias com base em modelos processuais de escrita, destacando a necessidade de uma "explicitação de características de tipologias, tendo em vista um domínio multifuncional desta competência, transversal e crucial para o sucesso na vida académica" (Sousa, 2011, p. 13). Também Duarte (2008, pp. 9-10) afirma que "Os alunos devem ser capazes de escrever textos bem articulados de diferentes tipologias [...] Ora para serem textualmente competentes, os jovens têm de ter sido objeto de aprendizagens e treinos vários no que concerne várias questões de Linguística Textual...”.

Um texto é mais do que uma simples sequência de frases ou enunciados e a sua compreensão e produção estão ligadas a uma competência textual. Esta pode definir-se como a "... capacidade que um sujeito tem de distinguir um aglomerado incoerente de enunciados de um texto coerente, além de operacionalizar metatextualmente actividades como as de parafrasear, condensar ou contrair, resumir, avaliar da natureza incompleta ou interrompida de um texto, poder atribuir um título, saber classificar o texto segundo um tipo ou função textual" (Neves \& Oliveira, 2001, p. 17). À semelhança de outros autores (Adam, 1992; Duarte, 2008; Preto-Bay, 2005; Silva, 2012), também Morais (1997, p. 92) afirma que o reconhecimento das tipologias textuais facilita, por um lado, a escrita, atuando como "princípio estruturante ou organizador", e por outro lado orienta e simplifica a interpretação e compreensão de um texto, sendo que os escritores experientes não descuram estes pormenores. Silva (2012) acrescenta que os programas de línguas dos ensinos básico e secundário têm dado um destaque crescente a esta temática.

Perante tudo isto, Festas (2002, p. 178) sugere que "A pedagogia da escrita tem que partir de uma compreensão da sua complexidade cognitiva e incentivar a transformação do pensamento...". Em suma, o modelo de ensino da escrita de textos deverá integrar as suas diferentes dimensões/componentes, que não podem dissociar-se ou ser postas de parte, bem como estender-se às diferentes tipologias textuais.

As estratégias de autorregulação e as estratégias que incidem nos diferentes processos da escrita e sua coordenação têm demonstrado a sua eficácia nesta área (Festas, 2002). Assim, e tal como lembra Preto-Bay (2005) é fundamental que o ensino da escrita seja explícito e se centre nos processos que os escritores experientes utilizam no processo de escrita, adaptando-os aos diferentes tipos de textos.

\section{O modelo Self-Regulated Strategy Development (SRSD)}

Tendo surgido em 1982, nos Estados Unidos da América (EUA), e vindo a ser desenvolvido e aperfeiçoado desde então, o SRSD ajuda os alunos a aprenderem estratégias específicas de escrita (e. g., planificação, revisão) e de autorregulação (e. g., estabelecimento de objetivos, automonitorização, autoinstrução, autorreforço, autoavaliação) (Graham \& Perin, 2007; Harris et al. 2011).

Este programa pode ser aplicado a partir do momento em que o aluno saiba ler e escrever, até um nível superior de ensino, quer em contexto de sala de aula, com pequenos grupos, individualmente ou em tutoria (Harris et al., 2011; Harris et al., 2012). Salienta-se a abrangência da sua intervenção que, além da escrita, pode ser utilizada na leitura, na soletração ou na matemática (Harris et al., 2008).

No que respeita à escrita, os grandes objetivos do SRSD são: ajudar os alunos no domínio dos diferentes processos cognitivos envolvidos nesta tarefa (e. g., planificação, produção, revisão e edição), relativamente a textos de diferentes tipologias; auxiliar os alunos no desenvolvimento de atitudes autorregulatórias que os tornem capazes de monitorizar e gerir a sua escrita; e potenciar o desenvolvimento de atitudes positivas perante a composição escrita e sobre si próprios enquanto escritores. São introduzidas mnemónicas para ajudarem os alunos a recordar as estratégias necessárias à melhoria do desempenho na escrita.

A instrução desenvolve-se ao longo de seis estádios Desenvolver e ativar os conhecimentos prévios; Discutir; Modelar; Memorizar; Apoiar; e Desempenho autónomo que podem ser reordenados, modificados, repetidos ou eliminados, de acordo com as necessidades dos alunos (Harris et al., 2008; Harris et al., 2011). Estes são, portanto, flexíveis, funcionando como linhas orientadoras e não etapas fixas e pré-determinadas.

No primeiro estádio - Desenvolver e ativar os conhecimentos prévios - são ensinados os conhecimentos prévios necessários para que os alunos usem as estratégias com sucesso. 
Segue-se o segundo estádio - Discutir - onde as estratégias, bem como os seus objetivos e vantagens, são descritas e discutidas.

Já no terceiro estádio - Modelar - o professor modela a utilização das estratégias.

No quarto estádio - Memorizar - os alunos memorizam os passos das estratégias através das mnemónicas que lhes estão associadas.

No quinto estádio - Apoiar - o professor apoia os alunos a dominarem as estratégias ensinadas.

Finalmente, no sexto estádio - Desempenho autónomo - os alunos já utilizam as estratégias com pouco ou nenhum apoio.

Segundo Harris et al. (2011), no SRSD, a instrução tem cinco características relevantes: 1) o ensino e o desenvolvimento explícitos dos conhecimentos sobre a escrita e sobre estratégias de escrita e autorregulação; 2) os alunos são vistos como colaboradores ativos, trabalhando com o professor e com os colegas; 3) a instrução é individualizada, pelo que os processos, as competências e os conhecimentos-alvo da instrução, são adaptados às necessidades e capacidades dos alunos; 4) a instrução é baseada em critérios e não no tempo; 5) o SRSD é um processo em desenvolvimento, onde são introduzidas novas estratégias e atualizadas as já ensinadas.

Ao longo da instrução, os professores promovem a manutenção e generalização/ transferência das aprendizagens. Assim os alunos são incentivados: a identificar oportunidades para usar as estratégias de escrita e autorregulação em outras aulas ou contextos; a discutir essas possíveis tentativas de utilização das estratégias e de que forma estas podem ser adaptadas em contextos diferentes; a avaliar o seu êxito durante e após a instrução (Harris et al., 2011).

Investigações sobre o SRSD demonstraram a sua eficácia em cinco aspetos do desempenho dos alunos: na inclusão de elementos de tipologias textuais; na qualidade da escrita; no conhecimento sobre a escrita; na abordagem à escrita; e na própria autoeficácia demonstrada nesta tarefa (Harris et al., 2011).

Além dos EUA, este modelo de instrução foi alvo de investigações em vários países (e. g., Portugal, Alemanha, Turquia, Egito), tendo ficado patente a sua eficácia. Em Portugal, foi objeto de estudo em algumas universidades, contudo destacamos o Projeto "Ensino de Estratégias de Escrita" (PTDC/CPE-CED/102010/2008), desenvolvido por investigadores da Universidade de Coimbra (Ferreira et al., 2012; Festas et al., 2015; Sousa et al., 2012) e que trabalhou o ensaio de opinião.

\section{Método}

Para a prossecução do projeto $O$ ensino da escrita através do Programa de Desenvolvimento de Estratégias de Autorregulação (SRSD) (SFRH/BD/84392/2012), recorreu-se a uma metodologia quase-experimental com pré-testes, pós-teste e follow-up.

Os objetivos gerais desta investigação foram: adaptar as estratégias do SRSD referentes à planificação e composição escrita do ensaio de opinião e do texto expositivo e verificar os efeitos da sua instrução em alunos do $8 .^{\circ}$ ano de escolaridade (Ferreira et al., 2014).

\section{Participantes}

Alunos. Participaram neste estudo cerca de 220 alunos do $8 .^{\circ}$ ano de escolaridade, de duas escolas públicas da área urbana do concelho Coimbra (Portugal). Contudo, após a recolha dos consentimentos informados, constituiu-se a amostra de 185 alunos, os quais estão divididos em grupo experimental $(n=122)$ e grupo de controlo $(n=63)$ (cf. Tabela 1$)$. O grupo experimental tem um número de sujeitos bastante maior do que o grupo de controlo, em virtude do número de turmas do 8. ${ }^{\circ}$ ano de escolaridade existentes em ambas as escolas.

Quanto ao sexo, verifica-se a predominância de elementos do sexo feminino $(n=37)$, na escola de controlo, enquanto na escola experimental, a predominância é masculina $(n=64)$ (cf. Tabela 1$)$.

Tabela 1.Distribuição dos alunos por sexo

\begin{tabular}{lccc}
\hline & Raparigas & Rapazes & Totais \\
\hline Grupo Experimental & 58 & 64 & 122 \\
Grupo de Controlo & 37 & 26 & 63 \\
Totais & 90 & 95 & 185 \\
\hline
\end{tabular}

No total estiveram envolvidas 10 turmas $(n=7$ experimental; $n=3$ de controlo).

Professores. Seis docentes de Português $(n=5$ experimental; $n=1$ de controlo) colaboraram nesta investigação, todas do sexo feminino. Quanto às habilitações literárias, todas são licenciadas, sendo a média de anos de ensino de 28,5.

À semelhança da distribuição do número de alunos pelos dois grupos, também a disparidade do número de professoras, por grupo, se deve a questões de organização de cada escola.

\section{Procedimento e Materiais}

Em primeiro lugar, solicitaram-se as autorizações necessárias à realização de uma investigação em contexto escolar (i. e., Direção Geral de Educação, agrupamentos de escolas, encarregados de educação). Adicionalmente, e como o estudo continha uma componente de formação de professores, pediu-se a acreditação da mesma junto do Conselho Científico-Pedagógico da Formação Contínua, cujo parecer foi favorável.

Para a elaboração das lições dos dois projetos de escrita, utilizaram-se os materiais do manual Powerful writing stategies for all students (Harris et al, 2008), onde, além de uma componente teórica sobre o modelo de instrução SRSD, constam lições e materiais para o ensino da composição escrita de diferentes tipos de texto. As lições referentes ao texto expositivo, direcionadas ao grupo experimental, foram adaptadas para a língua e contexto cultural portugueses, estando em consonância com o programa de Português do $8 .^{\circ}$ ano de escolaridade. Por outro lado, utilizámos as estratégias de ensino de escrita do ensaio de opinião do SRSD, destinadas ao 
grupo de controlo, desenvolvidas e testadas no âmbito de um projeto anterior (i. e., Projeto Ensino de Estratégias de Escrita/PTDC/CPE-CED/102010/2008), que foram alvo de algumas reformulações tendo em conta os objetivos desta investigação. Deste trabalho resultaram duas pastas com materiais teóricos e exercícios destinadas aos alunos e duas pastas com os materiais do professor que continham os guiões descritivos e orientadores das lições e instrumentos de apoio. Estas diferenciaram-se ao nível do conteúdo que era exclusivo de uma das tipologias de texto em estudo (i.e., ensaio de opinião e texto expositivo). Às professoras foi também cedido um exemplar da pasta do aluno da tipologia atribuída às suas turmas.

Os projetos foram lecionados pelas professoras de Português das turmas envolvidas. Estas participaram numa Oficina de Formação, a cargo da investigadora responsável pelo Projeto, com a duração de 50 horas, para aprenderem a implementar as estratégias de escrita e de autorregulação do SRSD. A formação contemplou, na fase prévia à intervenção, uma componente teórica que abordava os princípios pedagógicos do SRSD, e que era comum a todas as professoras, e sessões específicas que decorreram antes e durante a intervenção, realizadas em cada uma das escolas, em que foram trabalhadas exclusivamente as estratégias da tipologia de texto atribuída.

No grupo experimental, foram ensinadas as estratégias do texto expositivo através de duas mnemónicas: PLANO (Prestar atenção às instruções; Listar as ideias principais; Acrescentar ideias de apoio; Numerar os pontos principais pela e Ordem em que vão ser abordados) e ESCRITA (Elaborar o tema a partir do PLANO; Seguir os objetivos; Conectar as ideias com palavras de ligação; Redigir frases simples e complexas; Introduzir vocabulário diversificado; Terminar, Apresentando a conclusão/sintese).

No projeto de escrita do ensaio de opinião, os alunos do grupo de controlo trabalharam as estratégias gerais de planificação do ensaio com base na mnemónica PODE (Pegar na minha ideia; Organizar as minhas notas; Dizer e Escrever mais). Em complementaridade, com a mnemónica TRAVE (Tema; Razões; Acabar; Ver para Examinar), foram ensinadas as estratégias específicas daquele tipo de texto.

As doze sessões de cada um dos projetos decorreram semanalmente, nas aulas de Português, e tiveram a duração de 45 minutos. Após cada sessão, as professoras preencheram uma lista de verificação, com todos os passos previstos para essa sessão, onde tiveram de confirmar a sua realização ou informar a equipa, caso tivessem realizado atividades foram do previsto (e. g., repetição de alguma atividade realizada anteriormente, para consolidação das aprendizagens). Em algumas sessões, estiveram presentes dois elementos da equipa de investigação que coadjuvaram as professoras no apoio aos alunos e que, também preencheram a mesma lista de verificação. Assim, será possível cruzar dados de forma a averiguar a concordância das avaliações feitas por dois avaliadores.

Para assegurar a estandardização dos procedimentos e das atividades, os elementos da equipa de investigação supervisionaram e orientaram, semanalmente, o trabalho das professoras. Os procedimentos de implementação do projeto foram reajustados sempre que necessário.

De acordo com a metodologia desta investigação, os alunos tiveram três momentos de avaliação, onde cada um escreveu um texto expositivo e um ensaio de opinião, cujos temas, todos diferentes, foram aleatorizados. Pretendia-se avaliar as competências de escrita dos alunos, nas duas tipologias de texto, em cada um dos momentos de forma a determinar o impacto das aprendizagens de cada um dos projetos de escrita. Assim, no primeiro momento, prévio à intervenção, realizaram-se os pré-testes; no final da intervenção os pós-testes; e, finalmente, a última avaliação (follow-up), decorreu um mês após a realização dos pós-testes. No total, cada aluno escreveu três ensaios de opinião e três textos expositivos diferentes.

Para avaliar a perceção dos alunos face ao projeto de escrita, construiu-se o Questionário de Satisfação dos Alunos com o Projeto que foi preenchido durante e depois da intervenção. Ao mesmo tempo, aplicou-se a escala Envolvimento dos Alunos na Escola: Uma escala quadri-dimensional (EAE-E4D) (Veiga, 2013).

Também as professoras preencheram, durante e após a intervenção, o Questionário de Satisfação dos Professores com o Projeto, construído para o efeito, que além de itens específicos relativos ao projeto, continha uma primeira parte com dados sociodemográficos e de cariz profissional.

No decurso do projeto e de forma a caracterizar a amostra, recolheram-se os dados sociodemográficos dos alunos com recurso a uma Ficha Sociodemográfica, construída para o efeito.

Sendo um dos objetivos desta investigação verificar a transferência das aprendizagens para outras disciplinas/domínios, foram recolhido testes de avaliação sumativas das disciplinas de Ciências Naturais, História, Geografia e Físico-Química, para posterior análise.

Os textos escritos pelos alunos (pré-testes, pós-testes e follow-up) foram todos codificados e transcritos (com correção de erros ortográficos) para um ficheiro Word, onde, além do tema, se contaram as palavras. Quanto à sua avaliação, foram construídas duas grelhas, uma para cada tipologia, que têm vindo a ser preenchidas por dois avaliadores, treinados para esta tarefa. $\mathrm{Na}$ avaliação do texto expositivo, e por cada uma das partes estruturais (introdução com uma apresentação do tema; um corpo de texto bem desenvolvido, com ideias principais e ideias de apoio que explicitem as anteriores; e conclusão/síntese), atribui-se um ponto. Contabiliza-se também o número de conectores usados, bem como o número de frases complexas. Quanto ao ensaio de opinião, registam-se apenas os seus elementos estruturais (premissa sobre o tema proposto; número de razões abonadas a favor da premissa; número de elaborações de cada razão; e uma conclusão validando a premissa), atribuindo-se, quando presentes, um ponto.

\section{Resultados Esperados}

Encontramo-nos, ainda, na fase de tratamento de dados, pelo que, neste texto, não se apresentam resultados. 
Contudo, esperamos que, à semelhança de vários estudos realizados um pouco por todo o mundo, inclusivamente em Portugal, se comprove que o ensino de estratégias para a composição escrita, com recurso ao modelo SRSD, é eficaz na melhoria da qualidade de escrita, independentemente das características dos alunos, do ano de escolaridade que frequentam ou do tipo de texto trabalhado.

Especificamente, com este trabalho, esperamos que os alunos apresentem melhores resultados na tipologia trabalhada no seu grupo e não na outra. E que, por outro lado, os alunos que trabalharam o texto expositivo revelem uma maior evolução ao nível da escrita em outras disciplinas, quando comparados com o grupo de controlo.

\section{Referências}

Adam, J. M. (1992). Les textes: Types et Prototypes Récit, description, argumentation, explication et dialogue. Paris: Nathan.

Carvalho, J. A. B. (2002). Tipologias do escrito: A sua abordagem no contexto do ensino-aprendizagem da escrita na aula de língua materna. In Mello, C., Pereira, I., Santana, M. H., Carvalho, M. J., Brito, F. (Coord.), II Jornadas Científico-Pedagógicas de Português (pp. 89-99). Coimbra: Almedina.

Duarte, I. M. (2008). Ensino da língua portuguesa em Portugal: o texto, no cruzamento dos estudos linguísticos e literários. In Língua Portuguesa: educação \& mudança. Rio de Janeiro: Editora Europa, 210-232. Versão eletrónica, consultada a 17.11.13, em http://ler.letras.up.pt/uploads/ficheiros/5789.pdf

Ferreira, S., Prata, M., Inácio, M., Sousa, C., Festas, M. I., \& Oliveira, A. L. (2012). Ensino de estratégias de escrita em aulas de Língua Portuguesa. Actas da I Conferência Internacional Investigação, Práticas $e$ Contextos em Educação (pp. 109-113). Leiria: ESECS - Instituto Politécnico de Leiria.

Ferreira, S., Damião, M. H., Prata, M., \& Brites, T. (2014). O ensino de estratégias de autorregulação e de escrita do texto expositivo e do ensaio de opinião no $8 .^{\circ}$ ano de escolaridade. Atas do XII Congresso da SPCE (pp. 1657-1663). Vila Real: UTAD.

Festas, I. (2002). Principais tendências no ensino da escrita de textos, Psychologica, 30, 173-185.

Festas, I., Oliveira, A., Rebelo, J. A., Damião, H., Harris, K., Graham, S. (2015). Professional development in Self-Regulated Strategy Development: Effects on the writing performance of eighth grade portuguese students. Contemporary Educational Psychology, 40, 17-27. DOI: 10.1016/j.cedpsych.2014.05.004.

GAVE (2011). Provas de Aferição $2^{\circ}$ ciclo - Língua Portuguesa. Lisboa: Ministério da Educação.

GIASE (2004/2005). Estatísticas da Educação 04/05. Lisboa: Ministério da Educação.

Graham, S. \& Perin, D. (2007). Writing next: Effective strategies to improve writing of adolescents in middle and high school - A report to Carnegie Corporation of New York. Washington: Alliance For Excellent Education.

Harris, K. R., Graham, S., Manson, L. \& Friedlander, B. (2008). Powerful Writing Strategies for all Students. Baltimore: Paul H. Brookes Publishing Co.

Harris, K., Graham, S., MacArthur, C., Reid, R., Mason, L. (2011). Self-Regulated Learning Process and Children's Writing. In Zimmerman, B. \& Schunk, D. (Ed.), Handbook of Self-Regulation of learning and performance (pp. 187-202). New York: Routledge.

Harris, K., Lane, K., Graham, S., Driscoll, S., Sandmel, K., Brindle, M. \& Schatschneider (2012). PracticeBased Professional Development for Self-Regulated Strategies Development in Writing: a randomized controlled study. Journal of Teacher Education, 63 (2), p. 103-119.

Morais, M. F. A. (1997). Análise Temática-Contributo para o estudo das diferenças textuais, Faculdade de Letras, Universidade de Coimbra, Coimbra, Portugal.

Neves, D. R. \& Oliveira, V. M. (2001). Sobre o texto: Contribuições teóricas para práticas textuais. Porto: Edições ASA.

Niza, I.; Segura, J.; Mota, I. (2011). Escrita - Guião de Implementação do Programa. Lisboa: ME /DGIDC.

Preto-Bay, A. M. R. (2005). Alguns aspectos pedagógicos do ensino da escrita: o processo e o género textual. Revista Portuguesa de Pedagogia, 39 (1), 7-27.

Silva, P. N. (2012). Tipologias textuais: como classificar textos e sequências. Coimbra: Almedina.

Sousa, H. D. (coord.) (2012). Exames nacionais Relatório 2011. Lisboa: GAVE.

Sousa, C., Inácio, M., Ferreira, S., Prata, M., Festas, M., \& Oliveira, A. (2012). O modelo Self-Regulated Strategy Development no ensino da escrita do ensaio de opinião. Actas do $12^{\circ}$ Colóquio Internacional de Psicologia e Educação (pp. 1284-1295). Lisboa: ISPA.

Veiga. F. H. (2013). Envolvimento dos alunos na escola: Elaboração de uma nova escala de avaliação. International Journal of Developmental and Educational Psichology, 1 (1), pp. 441-450.

\section{Agradecimentos}

Este trabalho de investigação não seria possível sem a colaboração das duas escolas envolvidas, pelo que muito agradecemos às suas direções pelo interesse e oportunidade.

Também, aos encarregados de educação, queremos agradecer a confiança que demonstraram, autorizando os seus educandos a participar no estudo.

Às professoras manifestamos a nossa gratidão pelo esforço, dedicação e por todo o trabalho meritório.

Finalmente, uma palavra de reconhecimento aos alunos que tão bem abraçaram as tarefas propostas. 